\title{
APLICAÇÃO DE ALGORITMOS GENÉTICOS NA DETERMINAÇÃO DA OPERAÇÃO ÓTIMA DE SISTEMAS HIDROTÉRMICOS DE POTÊNCIA
}

\author{
Patricia Teixeira Leite ${ }^{* \dagger}$ \\ patricia.tleitedyahoo.com.br
}

\author{
Adriano A. F. M. Carneiro ${ }^{\dagger}$ \\ adrianodsel.eesc.sc.usp.br
}

\author{
André C. P. L. F. Carvalho $\ddagger$ \\ andredicmc.usp.br \\ *Universidade Federal do ABC \\ Centro de Engenharia, Modelagem e Ciências Sociais Aplicadas \\ Rua Santa Adélia, 166 - Bairro Bangu \\ CEP 09.210-170, Santo André, São Paulo, Brasil \\ ${ }^{\dagger}$ Laboratório de Sistemas Elétricos de Energia, Departamento de Engenharia Elétrica \\ Escola de Engenharia de São Carlos, Universidade de São Paulo \\ Av. trabalhador São Carlense, 400: 13566-590, São Carlos, São Paulo, Brasil \\ ${ }^{\ddagger}$ Laboratório de Inteligência Computacional \\ Instituto de Ciências Matemáticas e de Computação de São Carlos \\ Universidade de São Paulo, São Carlos, São Paulo, Brasil
}

\begin{abstract}
This paper investigates the application of Genetic Algorithms in the Optimization of the Operation Planning of Hydrothermal Power Systems. The aim of this work to analyze the application of this technique in a complex problem of high dimension, composed by several plants, belonging to different cascades. The authors believe that, due to their simplicity, parallelism and generality, the Genetic Algorithms present a great potential for the resolution of the pointed problem. The tests were applied in two groups with plants belonging to the Brazilian Southeast System. The first considers only reservoir hydroelectric, in the total of 19 plants, and the second uses reservoir hydroelectric the and run-of-river capacity hydroelectric plants, composed by 35 plants.
\end{abstract}

Artigo submetido em 15/12/2002

1a. Revisão em 15/04/2004

2a. Revisão em 04/04/2006

Aceito sob recomendação do Editor Associado

Prof. Glauco Nery Taranto
KEYWORDS: Hydrothermal Power Systems, Operation Planning, Optimization, Genetic Algorithms.

\section{RESUMO}

Este artigo investiga a aplicação de Algoritmos Genéticos na Otimização da Operação de Sistemas Hidrotérmicos de Potência, com objetivo de analisar a aplicabilidade dessa técnica em grandes sistemas. Este é um problema complexo, de grande porte, composto por várias usinas interligadas e pertencentes a diferentes cascatas. Os autores acreditam que, devido à sua simplicidade, paralelismo e generalidade, os Algoritmos Genéticos apresentam um grande potencial para a resolução do problema apontado. Os testes foram aplicados em dois conjuntos com usinas pertencentes ao Sistema Sudeste Brasileiro. O primeiro considera 19 usinas a reservatório, e o segundo é composto por 35 usinas, sendo 19 a reservatório e as restantes a fio d'água. 
PALAVRAS-CHAVE: Sistemas Hidrotérmicos, Planejamento da Operação, Otimização, Algoritmos Genéticos.

\section{INTRODUÇÃO}

Os Sistemas Hidrotérmicos de Potência (SHP) normalmente são divididos em geração, distribuição e consumo. A geração pode ser obtida de forma hidroelétrica, térmica e, eventualmente, por importação de sistemas vizinhos. Toda a energia elétrica disponível é enviada através das linhas de transmissão para o atendimento da demanda, conforme ilustrado na Figura 1.

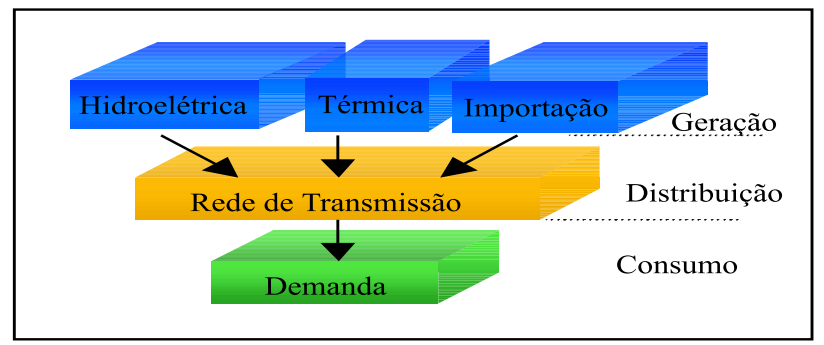

Figura 1: Sistema hidrotérmico

Com o crescimento acelerado da economia brasileira, fazse necessário um Planejamento da Operação cada vez mais avançado, que englobe as fontes de geração de energia, com objetivo de garantir, da melhor forma possível, o atendimento da demanda. Este é um grande desafio para os gerenciadores do Setor Elétrico, agravado inclusive pela recente crise de abastecimento de energia, para a qual contribuiu decisivamente a falta de investimentos que acompanhassem a evolução das necessidades.

Além disso, a decisão política de reestruturar o setor, com privatizações e desregulamentações, acompanhando algumas tendências internacionais, modificou bastante o ambiente de atuação das empresas de energia elétrica, trazendo novos e importantes desafios para o Planejamento da Operação.

Em sistemas com grande participação de geração hidroelétrica, como no caso do Brasil, pode-se utilizar a energia potencial da água armazenada nos reservatórios, gerenciandoa convenientemente, para atender a demanda e substituir de forma racional a geração dispendiosa das unidades térmicas.

Entretanto, o volume de água afluente aos reservatórios depende basicamente das afluências que irão ocorrer no futuro. Além disso, a disponibilidade de energia hidroelétrica é limitada pela capacidade de armazenamento nos reservatórios. Isso introduz uma relação entre uma decisão de operação em uma determinada etapa e as consequiências futuras desta decisão.

Por exemplo, segundo (Silva, 2001), se a decisão for utilizar energia hidroelétrica para atender o mercado e no futuro ocorrer uma seca, poderá ser necessário utilizar geração térmica de custo elevado ou interromper o fornecimento de energia. Por outro lado, se a opção for o uso mais intensivo de geração térmica, conservando elevados os níveis dos reservatórios, e ocorrerem vazões altas no futuro, poderá haver vertimento no sistema, que representa um desperdício de energia e, em conseqüência, um aumento desnecessário do custo de operação, conforme mostrado na Figura 2.

Devido às características do Sistema Brasileiro, o Planejamento da Operação de Sistemas Hidrotérmicos de Potência (POSHP) pode ser classificado como um problema de otimização dinâmico, de grande porte, com função objetivo não linear, não separável e não convexa, como mostrado por (Soares and Carneiro, 1991) e (Leite, 1999).

O objetivo do POSHP é determinar uma estratégia de geração para cada usina, que minimize o valor esperado dos custos operativos no período de planejamento e atenda a demanda dentro de um limite de confiabilidade. Desta forma, em sistemas com grande participação hidroelétrica, o objetivo econômico do planejamento da operação é substituir, na medida do possível, a geração de origem termoelétrica, de custo elevado, por geração de origem hidroelétrica, de custo praticamente nulo, de forma racional, como demonstrado por (Fortunato et al., 1990), (Carneiro et al., 1990) e (Perreira, 1985).

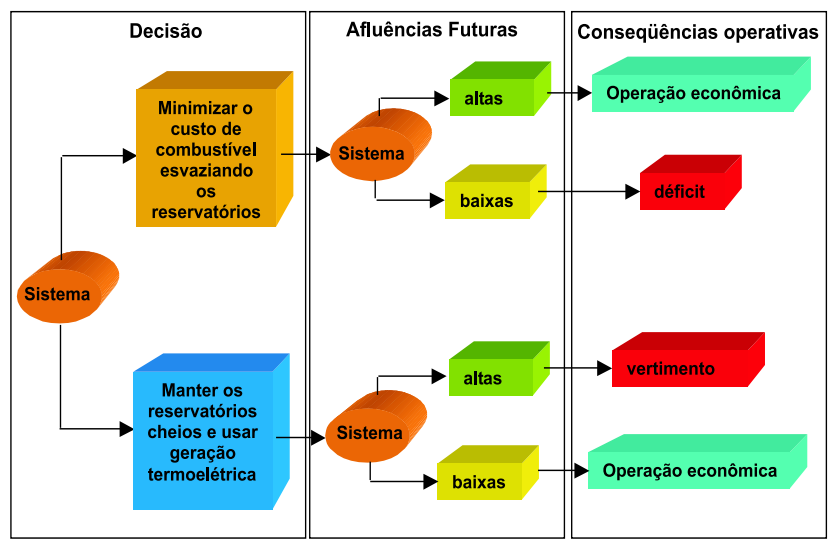

Figura 2: Cronograma de Decisão para SHP

As técnicas clássicas de otimização para solução deste problema podem apresentar algumas dificuldades, principalmente devido à complexidade da função objetivo. Assim, a busca de melhorias nos métodos tradicionais, ou de abordagens alternativas, visa aperfeiçoar esta etapa vital no funcionamento dos Sistemas Hidrotérmicos de Potência (Macieira et al., 2003), (Cicogna and Soares, 2003), (Martinez, 2001) e (Cicogna, 2003).

Outras metodologias envolvendo técnicas de Inteligencia Artificial (IA) vêem sendo investigadas e apontam a eficiência desta na solução de diversos problemas de otimização, den- 
tre eles pode-se destacar (Miranda et al., 1998), (Zoumas et al., 2004), (Chang and Chen, 1998), (Yang et al., 1996), e (Chen and Chang, 1996).

Portanto, esse trabalho trata da proposição de uma técnica de Inteligência Artificial no processo de otimização, baseada em Algoritmos Genéticos (AGs), voltada para o Sistema Brasileiro, o qual possui características especificas que o diferencia dos demais sistemas no mundo, motivando o estudo e desenvolvimento de abordagens mais apropriadas.

A próxima seção apresenta a formulação matemática da operação ótima. Na seção 3, alguns dos fundamentos da teoria de Algoritmos Genéticos são apresentados. Já na seção 4, é feita uma discussão do algoritmo proposto, bem como um breve comentário sobre a evolução da população. A seção 5 traz uma aplicação do método e análise dos resultados obtidos. Finalmente, na seção 6, são apresentadas as conclusões e observações finais do trabalho como um todo.

\section{FORMULAÇÃO MATEMÁTICA}

O problema do Planejamento da Operação de Sistema Hidrotérmicos de Potência pode ser formulado através de um modelo de otimização, onde o custo de operação dos sistemas hidrotérmicos é dado pelas termoelétricas, já que as usinas hidroelétricas têm custo de operação quase nulo, a menos de taxas, visto que seu "combustível" é a água. Na realidade neste custo pode incluir eventuais importações de energia e o custo do déficit, sem prejuízo das considerações e análises feitas.

Portanto, formulação geral do planejamento da operação energética de sistemas hidrotérmicos de potência pode ser estabelecida como a minimização do custo operacional do sistema, ao longo de todo o horizonte de planejamento $[1, T]$, dado por:

$$
\operatorname{Min} \sum_{t=1}^{T}[C(t)]
$$

onde:

$$
C(t)=C[D(t)-H(t)]
$$

para:

$$
D(t) \geq H(t)
$$

s.a.

$$
\begin{gathered}
H(t)=\sum_{i=1}^{N} \phi\left[x_{i}(t), q_{i}(t), z_{i}(t)\right] \\
q_{i}(t)+z_{i}(t)=u_{i}(t) \\
\phi_{i}\left(x_{i}, q_{i}, z_{i}\right)=K_{i}\left[h_{1 i}\left(x_{i}\right)-h_{2 i}\left(q_{i}+z_{i}\right)\right] q_{i}
\end{gathered}
$$

$$
\begin{gathered}
x_{i}(t+1)=x_{i}(t)+y_{i}(t)+ \\
\sum_{k \in \Omega_{i}}\left[q_{k}(t)+z_{k}(t)\right]-q_{i}(t)-z_{i}(t) \\
x_{i, \operatorname{mim}}(t) \leq x_{i}(t) \leq x_{i, \operatorname{máx}}(t) \\
q_{i}(t) \leq q_{i, \operatorname{máx}}(t) \\
u_{i, \min }(t) \leq q_{i}(t)+z_{i}(t)
\end{gathered}
$$

onde:

- $N$ - número de usina hidroelétricas;

- $\phi_{i}$ - função de geração hidroelétrica da usina $i$;

- $x_{i}(t)$ - volume do reservatório $i$ no intervalo $t$;

- $q_{i}(t)$ - vazão turbinada pela usina $i$ no intervalo $t$;

- $z_{i}(t)$ - vazão vertida da usina $i$ no instante $t$;

- $u_{i}(t)$ - vazão defluída da usina $i$ no instante $t$;

- $K_{i}$ - constante que engloba aceleração da gravidade, densidade da água, rendimento turbina-gerador e fatores de conversão de unidade;

- $h_{1 i}$ - altura de montante, em relação ao nível do mar, função do volume do reservatório;

- $h_{2 i}$ - altura de jusante, em relação ao nível do mar, função da vazão defluída total;

- $y_{i}(t)$ - afluência ao reservatório $i$ no instante $t$;

- $\Omega_{i}$ - conjunto de todas as usinas imediatamente a montante da usina $i$;

- $u_{i, m i ́ m}$ - representa a defluência total mínima obrigatória.

O estado final dos reservatórios é dado ou penalizado. Para resolução do problema apontado está sendo adotando uma técnica de IA baseada em Algoritmos Genéticos por (Leite et al., 2002a) e (Leite et al., 2003).

\section{ALGORITMOS GENÉTICOS}

Os Algoritmos Genéticos (AGs) foram introduzidos em meados de 1976 por John Holland e seus colaboradores da Universidade de Michigan; mas seu pleno desenvolvimento, só ocorreu a partir da década de 80 , através do trabalho de (Goldberg, 1989) 
Eles baseiam-se inicialmente na geração de uma população formada por um conjunto aleatório de indivíduos que podem ser vistos como possíveis soluções para um problema. Durante o processo evolutivo, esta população é avaliada: para cada indivíduo é dado um índice, refletindo sua habilidade de adaptação a um determinado ambiente. Uma porcentagem dos mais adaptados é mantida, enquanto os outros são descartados. Os membros selecionados podem sofrer modificações em suas características fundamentais através de mutações e cruzamentos genéticos, gerando descendentes para a próxima geração. Este processo, chamado de reprodução, é repetido até que um conjunto de soluções satisfatórias seja encontrado, como utilizado por (Goldberg, 1989) e (Beasley et al., 1993).

Os AGs são algoritmos de busca inspirados na Teoria da Seleção Natural. Eles atuam sobre uma população de indivíduos, baseados no fato de que indivíduos com boas características genéticas têm maiores chances de sobrevivência e de produzirem indivíduos cada vez mais aptos, enquanto indivíduos menos aptos tendem a desaparecer.

Para desenvolvimento e aplicação do algoritmo proposto para a solução do problema do Planejamento da Operação de Sistemas Hidrotérmicos de Potência foi necessária uma preparação e adaptação do problema, como será mostrado a seguir.

\section{ALGORITMO PROPOSTO}

Uma visão global do algoritmo proposto é apresentada na Figura 3, através de um fluxograma, com os passos seguidos para determinar o volume ótimo da usina, utilizando a técnica de Algoritmos Genéticos.

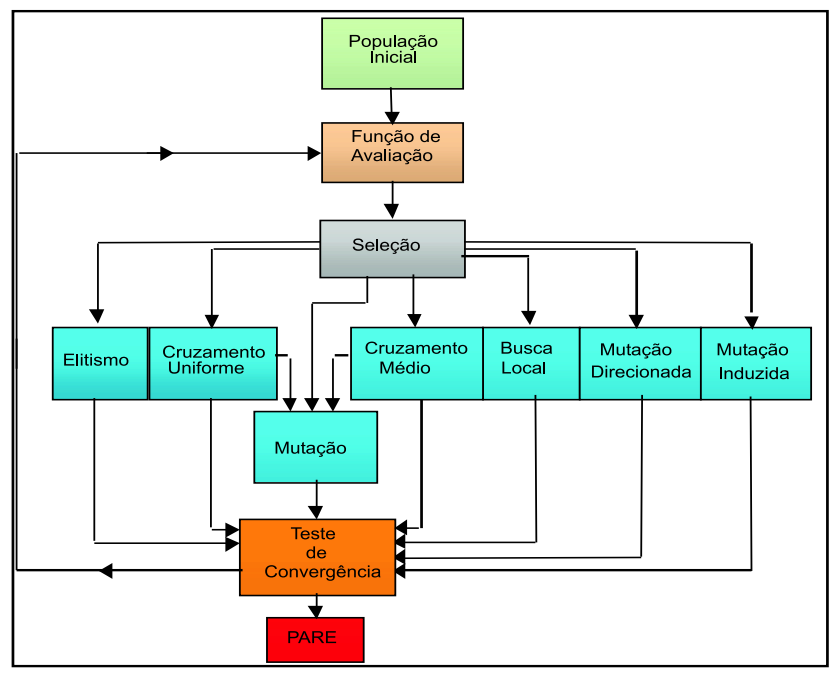

Figura 3: Algoritmo Proposto
O fluxograma mostra desde a entrada do algoritmo, com as aplicações dos operadores genéticos, cálculos das aptidões e formação de novas populações. A descrição detalhada dos principais procedimentos é apresentada a seguir.

Codificação do problema: a codificação do POSHP precisa ser realizada com cuidado, já que este é um problema interligado no tempo, pois a decisão tomada em um determinado período afeta diretamente todos os outros. Essa etapa é considerada a mais importante, pois a viabilidade do algoritmo depende da sua codificação. Para uma melhor representação do problema, adotam-se valores reais e não binários, como é usual, e o indivíduo representará o volume da usina em cada mês do planejamento.

Tamanho da população: o tamanho da população está diretamente relacionado com o desempenho global e a eficiência dos AGs (Haupt and Haupt, 1998). No problema apontado, após aproximadamente 840 testes com populações de tamanhos diferentes (12, 24 e 48 indivíduos), verificou-se que quanto maior a população, maior o tempo necessário para a convergência do algoritmo. No entanto, nos testes com populações de 24 e 48 indivíduos, os resultados foram próximos. Portanto, para conseguir executar o programa em um tempo menor, optou-se por utilizar uma população composta por 24 indivíduos (Leite et al., 2002b).

População inicial: a população inicial pode ser obtida de duas formas diferentes: aleatória ou volume sugerido, onde o volume é indicado pelo operador.

Função de avaliação: ou função de custo, está relacionada à minimização do valor da função objetivo do problema.

Ordenação da população:a população é classificada calculando o custo de todos os indivíduos e depois ordenandoos conforme o objetivo de minimização ou maximização do problema.

Seleção: na seleção, membros da população serão escolhidos para a aplicação de diversos tipos de operadores. Para cada operador, é selecionado um subconjunto dos indivíduos, que sofrerão aplicação dos diversos tipos de operadores genéticos, conforme 1 .

Os dados apresentados na 1 foram obtidos após vários testes com configurações diferentes (Leite et al., 2002b). A seguir é feita uma breve descrição dos operadores genéticos adotados.

Elitismo: para que os melhores indivíduos não sejam perdidos de uma geração para a outra, aplica-se o operador de elitismo. Isso garante que os melhores passem automaticamente para a próxima geração, preservando suas características genéticas.

Cruzamento uniforme: quando utilizam-se valores reais e 
Tabela 1: Dados utilizados na seleção

\begin{tabular}{|l|l|}
\hline Tamanho da população & 24 \\
\hline Operador genético & $\begin{array}{l}N^{o} \text { individuos } \\
\text { selecionados }\end{array}$ \\
\hline Elitismo & 1 \\
Cruzamento uniforme & 7 \\
Cruz. uniforme + mutação & 1 \\
Cruzamento médio & 7 \\
Cruzamento médio + mutação & 2 \\
Mutação & 3 \\
Mutação direcionada & 1 \\
Mutação induzida & 1 \\
Busca local & 1 \\
\hline
\end{tabular}

não binários, segundo apresentado por (Beasley et al., 1993), o cruzamento uniforme tem um melhor desempenho. Aproveitando este fato, nesse trabalho foi adaptado um tipo de cruzamento uniforme, sendo criado um filho a cada cruzamento, que garante, segundo uma taxa de probabilidade, que este tenha características dos dois pais ou mais características do melhor pai.

Cruzamento médio: com a finalidade de explorar o espaço de solução apresentado, foi implementado um tipo de operador genético, chamado cruzamento médio, onde as características genéticas do filho são obtidas segundo uma média ponderada das características dos dois pais. Essa ponderação fará com que as características genéticas deste, tenham valores próximos dos genes do melhor pai.

Mutação: com objetivo de manter a diversidade da população o operador genético de mutação é aplicado em alguns descendentes criados através de cruzamento uniforme, cruzamento médio e em alguns que não sofreram aplicação de nenhum tipo de operador. O operador de mutação é aplicado, com uma dada probabilidade, em cada gene do indivíduo, alterando o seu valor original.

Mutação direcionada: como se trata de um problema onde, quanto mais uniforme for a geração térmica, menor será o custo, faz-se um rastreamento de todos os valores de maior e menor geração (picos) ocorridos durante o período de planejamento e aplica-se mutação nestes pontos, de forma a manter o valor de geração o mais uniforme possível.

Mutação induzida: através de vários estudos são supostas conhecidas as características do comportamento ótimo das usinas em uma cascata. Como as usinas ocupam posições diferentes no conjunto, as características de operação são diferenciadas. As usinas a montante possuem a função de regularização do sistema, o que significa que podem oscilar o volume de seus reservatórios, a fim de proporcionar o enchimento dos reservatórios das usinas a jusante, mantendo-os cheios durante o período de planejamento.
Baseado no prévio conhecimento da operação ótima de sistemas hidrotérmicos, os indivíduos correspondentes às usinas a montante tem maior chance de variar o seu volume, enquanto as usinas a jusante permaneceriam cheias, informações estas que permitem uma redução do tempo computacional.

Busca local: como a aplicação foi feita em um problema complexo e de grande porte, para evitar que o algoritmo demore a convergir, a partir do momento em que tem-se um indivíduo que atenda a todas as restrições, é feita uma busca local. Isso ocorre a cada 100 iterações.

Nesta etapa, para os indivíduos com os mesmos valores de genes, somente um é mantido na população, enquanto os outros sofrerão alterações nas suas características com objetivo de explorar a vizinhança, ou seja, obter um outro indivíduo com características próximas do que foi descartado porém possivelmente mais próximo da solução ótima. Essas alterações seguem os mesmo mecanismos utilizados na mutação, respeitando uma taxa pré-determinada pelo operador. Neste caso todas as características serão alteradas.

\section{APLICAÇÃO}

O algoritmo proposto foi aplicado em dois sistemas testes. Um compostos por 19 usinas hidroelétricas e outro por 35, abrangendo grande parte do Sistema Sudeste Brasileiro, conforme apresentado na Figura 4. A potência instalada total para o menor sistema foi de $30.103 \mathrm{MW}$ e para o maior foi 36.271 MW.

Adotou-se como início de todos os períodos o mês de maio, inicio do período seco, e como final o mês de abril, final do período de afluências mais elevadas, coincidindo, portanto com o ano hidrológico.

As afluências adotadas, iguais a MLT (Média de Longo Termo), foram retiradas do arquivo de vazões do Sistema Brasileiro. O período de planejamento utilizado é de dois anos (24 meses), taxa de desconto de $10 \%$ a.a., e mercado variando ao longo do período.

Um subsistema incluindo somente as 19 usinas a reservatório foi testado no início, tendo-se posteriormente acrescentado as 16 usinas a fio d'água, com o objetivo de se verificar as interferências que poderiam surgir para o algoritmo, principalmente quanto ao crescimento do número de usinas.

Os testes foram realizados com um micro computador com 2 processadores Pentium III, $1 \mathrm{GHz}, 1 \mathrm{G}$ de memória RAM, com sistema operacional Windows 2000.

O objetivo do estudo foi o de analisar o comportamento do algoritmo desenvolvido, já testado em sistemas menores (Leite et al., 2002a), em um grande e complexo sistema, com muitas 


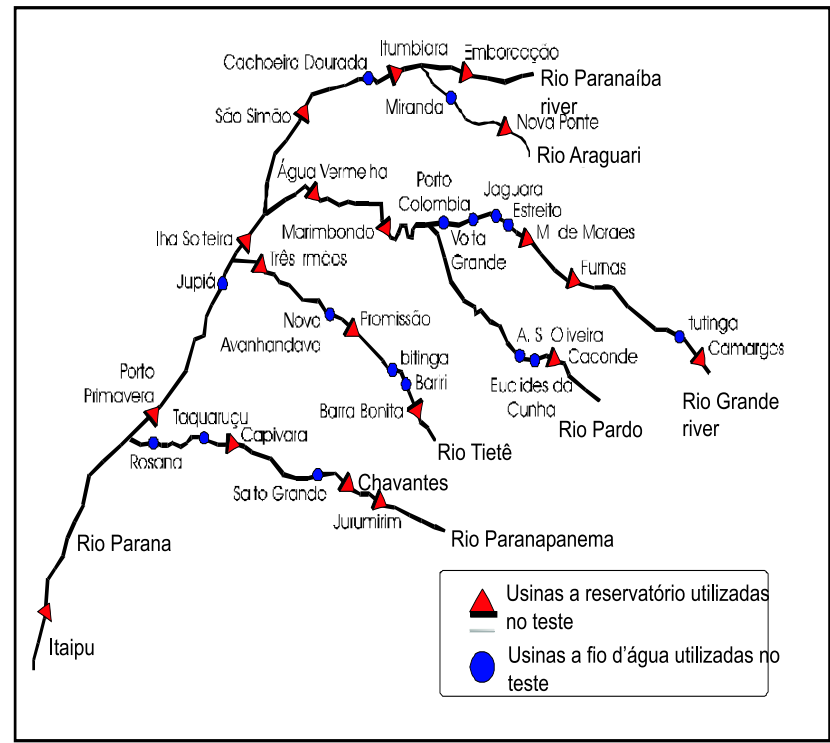

Figura 4: Parte do Sistema Sudeste

usinas de grande porte, interligadas em paralelo e em cascata, com dados reais e características típicas das usinas brasileiras.

Testes utilizando a técnica proposta neste artigo, com número de usinas distintos e afluências adotadas iguais ao histórico das vazões são apresentados em (Leite, 2003).

Os resultados obtidos foram plenamente satisfatórios podendo-se constatar o comportamento típico de uma operação otimizada, tanto individualmente como para o sistema total.

Assim, os comportamentos diferenciados das usinas, conforme suas posições relativas na cascata, ficaram bem evidenciados, com as usinas de montante regulando o sistema e as de jusante mantendo alta produtividade.

Na Figura 5 são mostradas algumas trajetórias de volumes obtidas do sistema teste composto por 19 usinas. Observe que as usinas de montante (Emborcação, Furnas e Chavantes), se encarregam da regulação do sistema, oscilando seus volumes de forma cíclica e atingindo os volumes máximos a cada final do período cheio.

No caso das usinas a jusante (São Simão, Marimbondo, Água Vermelha e Ilha Solteira), trabalham como usinas a fio d'água, mantendo o seu volume máximo, devido ao efeito cota. O mesmo comportamento pode ser observado na Figura 6 , no sistema teste composto por 35 usinas.

As usinas de montante (Itumbiara, Nova Ponte e Caconde) variaram os seus volumes ao longo do período de planejamento e as usinas a jusante (Marimbondo, Água Verme- lha, Ilha Solteira e Porto Primavera), mantiveram os volumes constantes, operando a fio d'água.

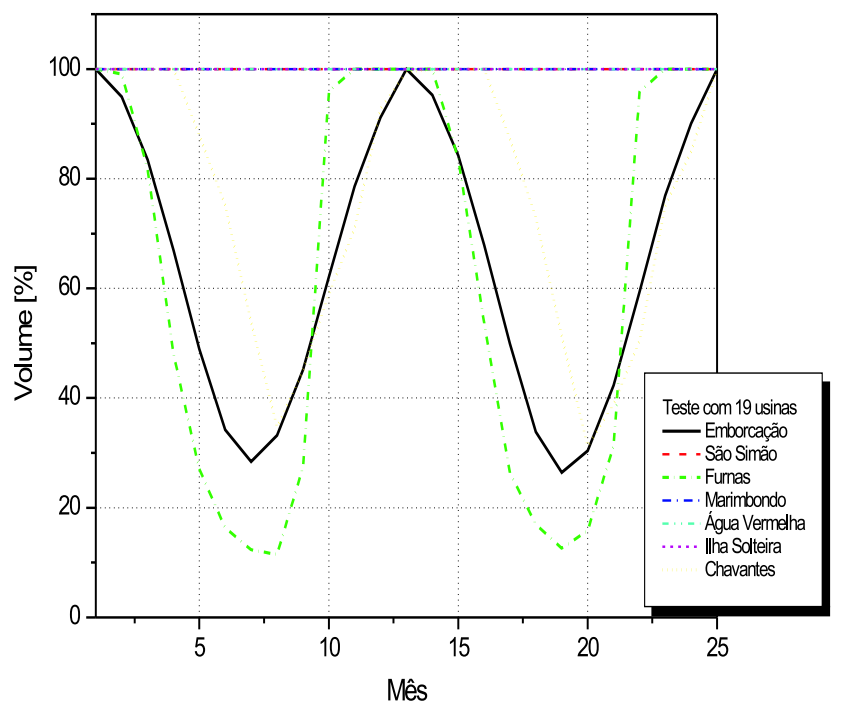

Figura 5: Trajetória de volume (19 usinas)

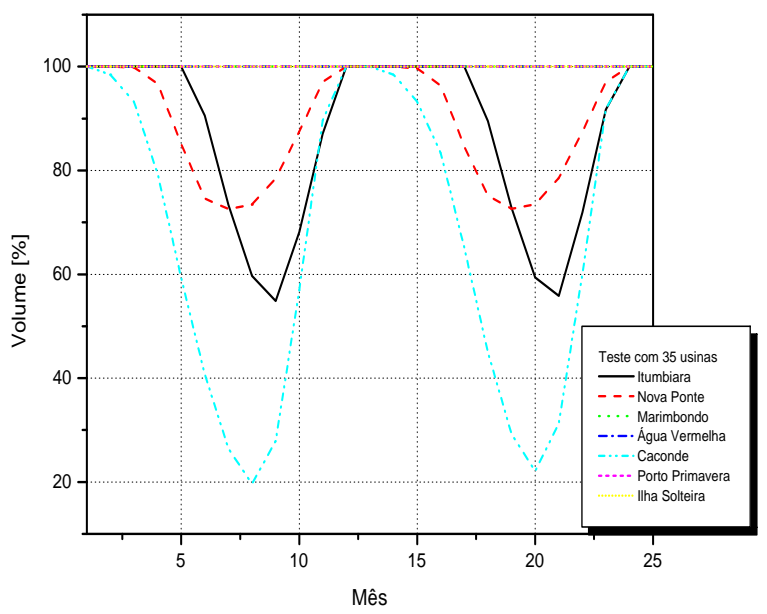

Figura 6: Trajetória de volume (35 usinas)

As trajetórias de geração hidráulica total são mostradas na Figura 7 para os dois sistemas testes, apresentando um comportamento típico de sistema otimizado.

Sabendo que o custo de operação é dado por uma função com crescimento exponencial, há a tendência de que, quanto mais uniforme for definida a complementação térmica, menor será o custo de operação.

Observe que o comportamento não se alterou significativamente com a introdução das usinas a fio d'água, mostrando a robustez do algoritmo para lidar com um grande número de usinas. 


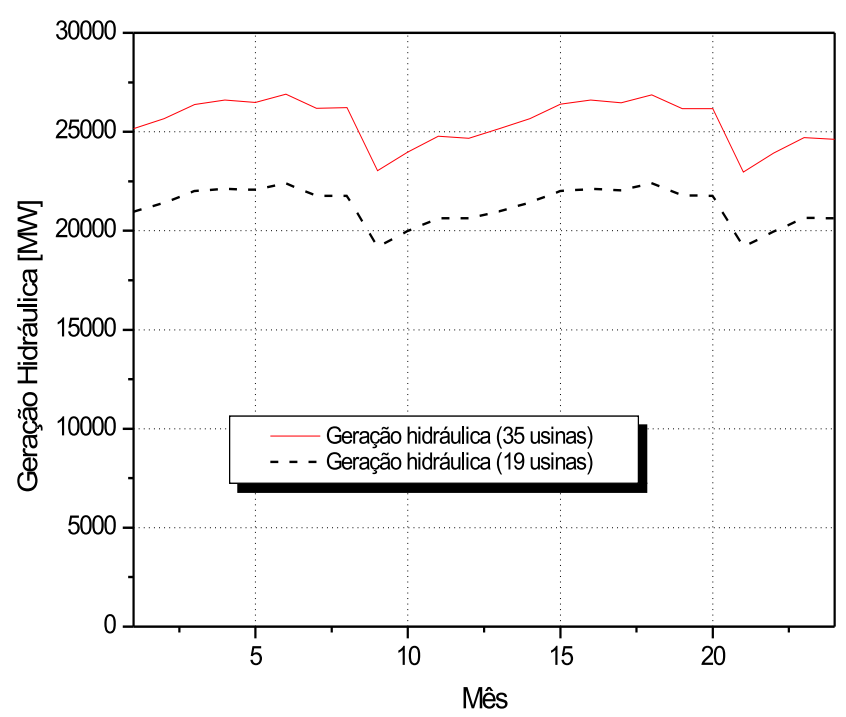

Figura 7: Geração hidráulica total

Essa característica de uniformidade térmica foi mantida pelos AGs, tanto no caso teste com apenas usinas a reservatório, como no conjunto total, conforme mostrado na Figura 8.

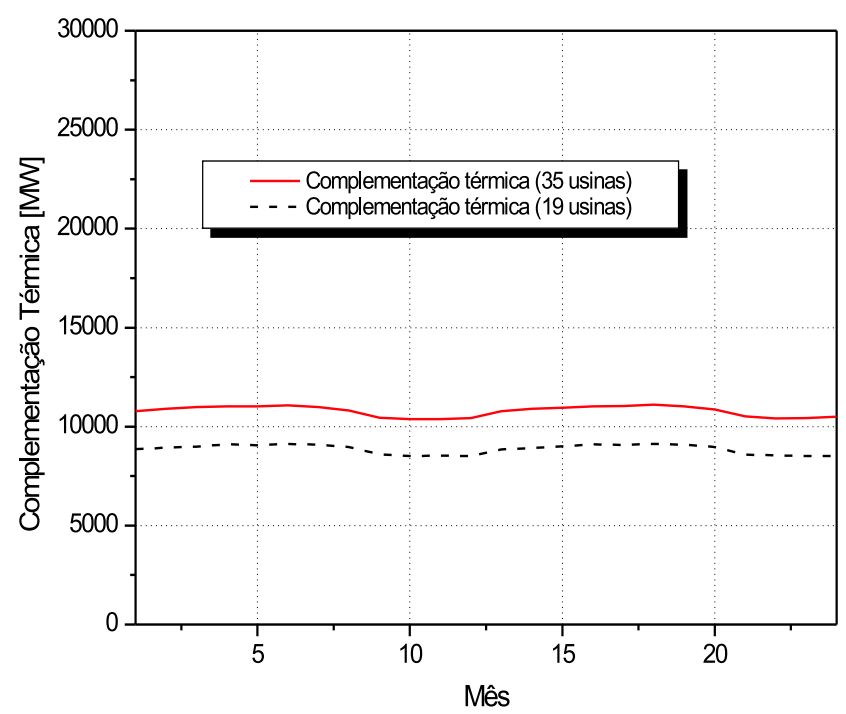

Figura 8: Complementação Térmica

\section{CONCLUSÕES}

Através dos resultados obtidos, observa-se que a nova técnica proposta, utilizando Inteligência Artificial, mostrou um bom desempenho nos casos apresentados que envolviam grandes e complexos sistemas.

A técnica permite uma representação individualizada das usinas, além de ser relativamente simples de ser aplicada, e o crescimento do número de usinas não afetou a eficiência do algoritmo, o que ocorre muitas vezes, quando se utiliza técnicas tradicionais de otimização.

$\mathrm{O}$ algoritmo conseguiu captar os diferentes comportamentos operativos ótimos das usinas, obtendo um ótimo global para o sistema.

Novos testes estão sendo desenvolvidos, em condições operativas diversas, e tudo indica que esta poderá ser uma técnica alternativa ou complementar no planejamento da operação.

\section{AGRADECIMENTOS}

Os autores agradecem o suporte técnico da FAPESP "Fundação de Amparo a Pesquisa do Estado de São Paulo"e ao Prof. Sadao Massago da Universidade Federal de São Carlos.

\section{REFERÊNCIAS}

Beasley, D., Bull, D. and Martin, R. (1993). An overview of genetic algorithms: Part 1, fundamentals, Technical report, Inter-University Commitee on Computing.

Carneiro, A. A. F. M., Soares, S. and Bond, P. S. (1990). A large scale application of an optimal deterministic hydrothermal scheduling algorithm, IEEE Trasaction on Power Systems 5(1): 204-210.

Chang, H.-C. and Chen, P.-H. (1998). Hydrothermal generation scheduling package: A genetic based approach, IEE Proceeding Generation Transmission Distribuition 145(4): 451-457.

Chen, P.-H. and Chang, H.-C. (1996). Genetic aided scheduling of hydraulically coupled plants in hydro-thermal coordination, IEEE Transactions on Power Systems 11(2): 975-981.

Cicogna, M. A. (2003). Sistema de Suporte a Decisão para o Planejamento e a Programação da Operação de Sistemas de Energia Elétrica, $\mathrm{PhD}$ thesis, Faculdade de Engenharia Elétrica, Universidade Estadual de Campinas, Campinas.

Cicogna, M. A. and Soares, S. (2003). Um sistema de suporte à decisão para o planejamento e a programação da operação de sistemas hidrotérmicos de potência, XVII SNPTEE - Seminário Nacional de Produção e Transmissão de Energia Elétrica .

Fortunato, L. A. M., Neto, A. and Alencar, T. (1990). Introdução ao Planejamento da Expansão e Operação de Sistemas de Produção de Energia Elétrica, NiteroiEduff.

Goldberg, D. E. (1989). Genetic Algorithms in Search Optimization and Machine Learning, 0201157675, Addison-Wesley Pub. Co. 
Haupt, R. and Haupt, S. E. (1998). Pratical Genetic Algorithms, John Wiley \& Sons, INC, NEW YORK.

Leite, P. T. (1999). Um algoritmo genético para o planejamento de sistemas hidroelétricos, Dissertação de mestrado, Escola de Engenharia de São Carlos.

Leite, P. T. (2003). Aplicação de Técnicas de Inteligência Artificial no Planejamento da Operação de Sistemas Hidrotérmicos de Potência, PhD thesis, Escola de Engenharia de São Carlos, Universidade de São Paulo, São Carlos.

Leite, P. T., Carneiro, A. A. F. M. and Carvalho, A. C. P. L. F. (2002a). Energetic operation planning using genetic algorithms, IEEE Trasaction on Power Systems 17(1): 173-179.

Leite, P. T., Carneiro, A. A. F. M. and Carvalho, A. C. P. L. F. (2002b). VII brazilian symposium on neural networks, IEEE Computer Society I.

Leite, P. T., Carneiro, A. A. F. M. and Carvalho, A. C. P. L. F. (2003). Sistemas Inteligentes - Fundamentos e Aplicações, solange oliveira rezende edn, Manole, Barueri, SP, Brasil.

Macieira, M. E. P., Marcato, R. M. and Marcato, A. L. M. (2003). Comparação entre abordagem estocástica e determinística no planejamento da operação de médio prazo de sistemas hidrotérmicos interligados, XVII SNPTEE - Seminário Nacional de Produção e Transmissão de Energia Elétrica .

Martinez, L. (2001). Política de Controle Malha Fechada e Malha Aberta no Planejamneto da Operação Energética de Sistemas Hidrotérmicos, PhD thesis, Faculdade de Engenharia Elétrica, Universidade Estadual de Campinas, Campinas.

Miranda, V., Srinivasan, D. and Proenca, L. M. (1998). Evolutionary computation in power systems - example 2: Genetic algorithms in hydrothermal operation planning, Eletrical Power \& energy Systems 20(2): 93-97.

Perreira, M. V. (1985). Overview - optimal scheduling of hydrothermal systems, IFAC Symposium on Planning and Operation of Electric Energy Systems pp. 1-9.

Silva, E. L. (2001). Formação de Preço em Mercados de Energia Elétrica, Editora Sagra Luzzatto.

Soares, S. and Carneiro, A. A. F. M. (1991). Optimal operation of reservoirs for electric generation, IEEE Transactions on Power Delivery 6(3): 1101-1107.
Yang, P.-C., Yang, H.-T. and Huang, C.-L. (1996). Scheduling short-term hydrothermal generation using evolutionary programming techniques, IEE Proceeding Generation Transmission Distribuition 143(4): 371-376.

Zoumas, C., Bakirtzis, A., Theocharis, J. and Petridis, V. (2004). A genetic algorithm solution approach to the hydrothermal coordination problem, IEEE Trasaction on Power Systems 19(2): 1356-1364. 